\title{
LXXIV. On the electrical conductivity imparted to liquid air by alpha rays
}

\section{Professor J.C. McLennan \& David A. Keys}

To cite this article: Professor J.C. McLennan \& David A. Keys (1913) LXXIV. On the electrical conductivity imparted to liquid air by alpha rays , Philosophical Magazine Series 6, 26:155, 876-894, DOI: $10.1080 / 14786441308635032$

To link to this article: http://dx.doi.org/10.1080/14786441308635032

曲 Published online: 08 Apr 2009.

Submit your article to this journal $₫$

Џ Article views: 4

Q View related articles $\square$

Citing articles: 3 View citing articles 5 
LXXIV. On the Electrical Conductivity imparted to Liquid Air by Alpha Rays. By Professor J. C. MoLennan and DAvid A. KFYs, University of 'Toronto *.

[Plate XVIII.]

\section{Introduction.}

$\mathrm{T}$ the published accounts of their experiments on the measurement of the dielectric constants of different liquefied gases, a number of investigators including Linde $\dagger$, Dewar and Fleming $\ddagger$, and Hasenöhrl $\S$, have drawn attention to the high insulating qualities possessed by such liquids. In particular, Fleming and Dewar have shown that a small condenser when immersed in liquid air and charged with a Wimshurst electrical machine held its charge perfectly for a period of some minutes. Quite recently, too, Zeeman $\|$, in studying the Kerr phenomenon in liquid air, found when the latter was freed from small ice and carbonicdioxide erystals by filtration, and when precautions were taken to prevent the generation of gas-bubbles between the electrodes, electric fields as high as 90,000 volts per $\mathrm{cm}$. and even higher ones could be maintained quite readily in the liquid.

Fleming and Dewar in the course of their experiments made a determination of the dielectric constant of liquefied air, and also that of liquid oxygen. The latter they found to be 1.495 . If we assume the density of gaseous oxygen at $15^{\circ} \mathrm{C}$. and $760 \mathrm{~mm}$. pressure to be 0.00134 (and its density at $-182^{\circ} \mathrm{C}$. consequently to be $0^{\circ} 00424$ ) and its dielectric constant at $0^{\circ} \mathrm{C}$. and $760 \mathrm{~mm}$. pressure to be 1.00059 , it follows by applying the Clausius-Mosotti relation,-1hat $\mathrm{K}-1$ is proportional to the density of the gas, - that the dielectric constant of gaseous oxygen at $-182^{\circ} \mathrm{C}$. and $760 \mathrm{~mm}$. pressure should be approximately $1 \cdot 0018$.

Moreover, as the density of liquid oxygen is about $1 \cdot 1375$, it follows if we assume the Clausius-Mosotti's Law to hold continuously in passing from the gaseous to the liquid phase, that the dielectric constant of liquid oxygen should be

* Communicated by the Authors. Read before the Royal Society of Canada, May 26, 1913.

† Linde, Wied. Ann. vol. lvi. p. 546 (1895).

I Dewar and Fleming, Proc. Roy. Soc. London, vol. lx. p. 358 (1896).

\$ Hasenöhrl, Leiden Comm. No. 52, Proc. Amst. Akad. of Sci. vol. xi. p. 211.

II Zeeman, Proc. Amst. Akad. of Sci. p. 650, Jan, 24, 1912. 
approximately $1 \cdot 4824$. This it will be seen is very close to the value found by Dewar and Fleming in their experiments.

In view of this continuity in the dielectric property of oxygen in passing through the stage of liquefaction, it was thought to be of interest by the writers to see if any indication of a similar continuity could be obtained in the ionization of air by alpha rays when passing from the gaseous to the liquid state. P. Curie *, Jaffe $\dagger$, Cäcilia Böhm-Wendt and E. von Schweidler $\ddagger$, and Bialobjeski $\S$, have shown that a conductivity can be impressed on certain dielectric liquids by gamma rays, but Greinacher || appears to have been the only investigator who has studied the ionization produced in such liquids by alpha rays. His experiments were made with paraffin oil and petrol ether.

Among other results he found :-

1. That the conductivity so impressed was independent of the direction of the current, and that therefore the mobilities of the positive and negative ions produced in these liquids by the alpha rays were practically identical.

2. That with petrol ether a saturation-current was obtained with a field of about 400 volts per $\mathrm{cm}$., but that in the case of petroleum oil complete saturation was not obtained even when fields as high as 10,000 volts per $\mathrm{cm}$. were applied : and

3. That the total ionization produced in air at atmospheric pressure when the alpha rays from a sample of polonium were completely absorbed, was about 2000 times as great as the total ionization produced in petrol ether when the radiation from the same polonium was completely absorbed by that liquid.

In the following paper an account is given of some preliminary experiments made on the ionization of liquid air by alpha rays, and from the results which are given below it will be seen that the findings of others are confirmed in regard to the high insulating power of liquid air. It will be shown, too, that the conductivity impressed by alpha rays on liquid air is similar in some regards to that obtained by Greinacher in lis experiments with petroleum and petrol ether traversed by alpha rays.

* Curie, $C$. $R$. vol. cxxxiv. p. 420 (1902).

$\dagger$ Jaffe, Ann. d. Phys. vol, xxviii. p. 326 (1909).

\pm Böhm-Wendt and Schweidler, Phys. Zeit. vol. x. p. 379 (1909).

\$ Bialobjeski, Le Radium, p. 293, Aug. 19I1.

Greinacher, Phys. Zeit. 10 Jahr. No. 25, p. 986. 


\section{Preliminary Experiments.}

In order to obtain an estimate of the insulating power of liquid air, a clean copper wire $\mathrm{A}$ was connected to earth and suspended in a Dewar flask C. A second copper wire B was also suspended in the flask in such a way as to touch neither the wire $\mathrm{A}$, nor the sides or the base of the flask $\mathrm{C}$. The wire $B$ was held in position by carefully cleaned ebonite supports. It was also connected to the free quadrants of a Dolazalek electrometer and to one of the armatures of a sulphur condenser of about 2300 e.s.u. capacity.

In one experiment with this arrangement the electrode $B$ and its connected system was charged when the flask was empty to one quarter of a volt by means of an auxiliary battery. The steady deflexion on the scale corresponding to this potential was $99.5 \mathrm{~mm}$. In order to test the insulating power of the system the connexion of the auxiliary battery was broken and the leak from the system observed for an hour. The rate was found to be $-48 \mathrm{~mm}$. per minute, which was not very high considering that the insulated system was supported by a number of pieces of ebonite and that the air in the room possessed a very considerable humidity, since the experiments were conducted in the summer time. The Dewar flask was then filled with carefully filtered liquid air and the electrode $\mathbf{B}$ and the connected system again charged to $\frac{1}{4}$ of a volt. The deflexion again was found to be 99.5 divisions, and when the auxiliary battery was disconnected the second time the leak from the system for an hour was found to be only at the rate of $56 \mathrm{~mm}$. per minute. This showed that the leak from the whole system was practically the same when the Dewar flask contained liquid air as when it contained only ordinary gaseous air at atmospheric pressure.

In a second set of experiments, the Dewar flask was in turn filled with amyl, ethyl, and methyl alcohol, and the electrode $B$ and attached system was joined, with each liquid in the flask in turn, to the $\frac{1}{4}$-volt auxiliary circuit. With the amyl alcohol the steady deflexion obtained under these circumstances was only $97.5 \mathrm{~mm}$., with ethyl alcohol $76 \mathrm{~mm}$., and with methyl $63 \mathrm{~mm}$. With these deflexions the current from the battery to the electrode was equal to the current from the electrode through the liquid to earth. In all three cases when the auxiliary charging current was disconnected, the electrode system at once lost its charge and the electrometer needle immediately returned to the zero position. 'These 
experiments show that of the three alcohols, the amyl was the best insulator and the methyl the poorest. The experiments also show that the liquid air was a very much better insulator than any of the three alcohols.

In another set of experiments a small air-condenser of ahout 100 e.s.u. capacity was made up of brass plates and inserted in a brass box, the latter being placed in a second box resting on and surrounded with wool. This condenser was charged to a potential of 894 volts with a battery of small storage-cells. When air at atmospheric pressure, carefully filtered liquid air, and xylene were in turn used as the dielectric, and the potential difference mentioned applied to the condenser, the chargo obtained in each case was ascertained by discharging the condenser through a sensitive ballistic galvanometer with a specially constructed key supported upon a paraffin block.

The deflexions obtained in a series of mensurements with the three dielectrics are given in Table $I$.

\section{Table I.}

\begin{tabular}{|c|c|c|c|}
\hline \multirow{2}{*}{$\begin{array}{l}\text { Charging } \\
\text { potential. }\end{array}$} & \multicolumn{3}{|c|}{$\begin{array}{c}\text { Deflexions on scale of galvanomoter with } \\
\text { different dielectrics. }\end{array}$} \\
\hline & $\begin{array}{l}\text { Air at atmo- } \\
\text { spheric pressure. }\end{array}$ & $\begin{array}{l}\text { Liquid } \\
\text { air. }\end{array}$ & Xylene. \\
\hline 894 volts. & $\begin{array}{l}11 \cdot 75 \mathrm{~mm} . \\
11 \cdot 75 \\
11 \cdot 4 \\
12 \cdot 0 \\
11 \cdot 6 \\
12 \cdot 0 \\
11 \cdot 50\end{array}$ & $\begin{array}{l}16.5 \mathrm{~mm} . \\
17.0 \\
16.75 \\
168 \\
167 \\
165 \\
165 \\
16.4 \\
16.7 \\
16.4\end{array}$ & $\begin{array}{l}21 \cdot 9 \mathrm{~mm} . \\
22 \cdot 2 \\
23 \cdot 0 \\
23 \cdot 0 \\
24 \cdot 0 \\
21 \cdot 0 \\
235 \\
22 \cdot 5 \\
23 \cdot 3 \\
24 \cdot 2\end{array}$ \\
\hline & Means $11 \cdot 71$ & 166 & $22 \cdot 86$ \\
\hline
\end{tabular}

These numbers, it will be seen, if we take the dielectric constants of air at atmospheric pressure to be unity, give 1.95 and 1.42 as the dielectric constants for xylene and liquid air respectively. The value obtained for liquid air is, therefore, about 50 per cent. lower than tlat given by Fleming and Dewar. 
III. Electrical Conductivity imparted to Liquid Air by Alpha rays.

(a). After we were satisfied from these preliminary experiments that the liquid air as used was quite free from any contamination which might impart a conductivity to it, a set of measurements was made with the apparatus shown in fig. 1. In this apparatus two copper plates, A and B, were

Fig. 1.

ve form-taElectromoter

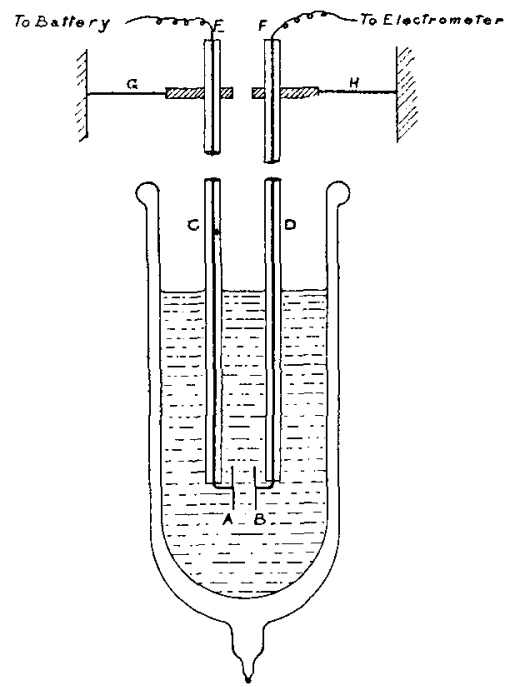

supported by two thick copper wires EA and FB. The former was surrounded with a glass tube, and the latter with a tube of clear fused quartz. Both were supported by pieces of ebonite carried by two metal rods, $G$ and $H$, attached to an earthed metal case which was large enough to contain all the apparatus. The wires $\mathrm{EA}$ and $\mathrm{FB}$ were made about $60 \mathrm{~cm}$. long, so that when the lower ends were immersed in liquid air their insulating supports, carried by the rods $G$ and $H$, were sufficiently far removed to prevent moisture depositing on them through their being cooled below the dewpoint and so spoiling the insulation at $G$ and $H$.

The electrode $\mathrm{EA}$ was connected to a battery of small storage-cells, and the electrode FB to the free quadrants of an electrometer. Before being used the electrodes and their supporting wires were all carefully cleaned.

In carrying out these experiments the liquid air was always carefully filtered and the measurements were made as 
rapidly as possible. This was done because even when the case was supplied with large quantities of $\mathrm{P}_{2} \mathrm{O}_{5}$ and concentrated sulphuric acid, moisture was always deposited on the glass and quartz tubes surrounding the wires at a point a short distance above the mouth of the Dewar flask, and whenever this deposit had gained a considerable thickness it was found that small pieces of ice and snow always fell from it into the Hask and lowered considerably the insulating power of the liquid air.

In using the apparatus a set of observations was taken immediately after the filtered liquid air was poured into the flask with a series of increasing potentials applied to the electrode EA. In every case it was found on doing this that practically no current passed through the liquid air. A small plate of copper about $1 \mathrm{sq} . \mathrm{cm}$. in area, having on it a deposit of poloninm which had previously been washed in water and dried, was then attached to the face of the electrode $B$ with the polonium facing the electrode A. A second series of readings was then taken with increasing potentials applied to EA. After this the copper plate carrying the polonium deposit was quickly removed and a third set of readings taken without it. A slight conductivity was generally obtained in this third set of readings, but its amount was found to depend very largely upon the time which was allowed to pass in taking the second and third sets of readings.

In the intervals between the first and second sets of readings and the second and third sets, care was taken to see that the deposit of snow and ice-crystals was removed from the glass and quartz tubes surrounding the wires leading to the electrodes. These tubes, the leading wires, and the electrodes were also thoroughly dried before they were inserted in the liquid air for the second as well as for the third sets of readings, in order to make certain that no moisture was introduced with them into the liquid air. All possible care was taken to prevent ice-crystals falling from the wires into the liquid air during the course of the measurements. But it was difficult to make certain that moisture did not deposit from the air upon the surface of the liquid air, and the small conductivity generally observed in the third set of readings was taken as an indication that such deposition was not entirely prevented.

The readings given in Table II. and the curves representing them in fig. 2 (PI. XVIII.) will serve to illustrate the variation obtained with different voltages in the current through the presence of the polonium in the liquid air. In this particular

Phil. Mag. S. 6. Vol. 26. No. 155. Nov. 1913. 30 
set of measurements the capacity of the electrode and the system connected with it was about 200 e.s.u., and the distance between the electrodes $A$ and $B$ was about $5 \mathrm{~mm}$.

TABLe II.

Conductivity imparted to Liquid Air by Alpha Rays from Polonium.

\begin{tabular}{|c|c|}
\hline $\begin{array}{c}\text { Potential difference applied } \\
\text { to electrode EA. }\end{array}$ & $\begin{array}{l}\text { Deffexion of electrometer } \\
\text { (volts per win.). }\end{array}$ \\
\hline $\begin{array}{l}1450 \text { volts (positive) } \\
1144 \\
912 \\
570 \\
329 \\
81 \\
405\end{array}$ & $\begin{array}{l}37.3 \times 10^{-2} \\
33.6 \quad " \\
28.5 \quad " \\
26.5 \quad " \\
24.3 \quad " \\
16.6 \quad " \\
11.6 \quad "\end{array}$ \\
\hline
\end{tabular}

From the form of the curve it will be seen that even with the highest voltages used saturation was not obtained. There is, however, a distinct bend shown in the curve in the region corresponding to about 150 volts.

It is difficult to give a complete explanation of this bend, but in all probability the phenonemon has to do either with a volume ionization produced in the liquid air by some unknown radiation of a penetrating type from the polonium, or by beta rays due to sume active impurity in the polonium. Possibly, too, it may have been due in part at least to a diffusion of ions into the body of the liquid air from the thin layer of ionization produced by the alpha rays close to the plate B. It is clear that moderate fields would in all probability suffice to remove all such ions from the field and so account for the bend. The gradual rise in the curve obtained with fields about 200 volts was no doubt due to the increasing influence exerted by the field in overcoming recombination in the ionized layer of liquid.

(b) In a second set of measurements the apparatus shown in fig. 3 was used. This consisted of a plate $\mathrm{GH}$ separated from a second plate $\mathrm{EF}$ by two small blocks of clean ebonite. The plate EF was provided with an opening shown in the figure somewhat over $1 \mathrm{sq} . \mathrm{cm}$. in area. A third plate CABD wis attached to EF by ebonite supports and was bent so that the portion $\mathrm{AB}$ occupied nearly all the space provided by the opening in FE. 
Conductivity imparted to Liquid Air by Alpha Rays. 883

A polonium-coated copper plate about $1 \mathrm{sq} . \mathrm{cm}$. in areat was attached in this case to $A B$, that portion of the plate $\mathrm{CABD}$ which lay within the opening in FE with its active face towards GH and with its surface in the plane of EF.

Fig. 3.

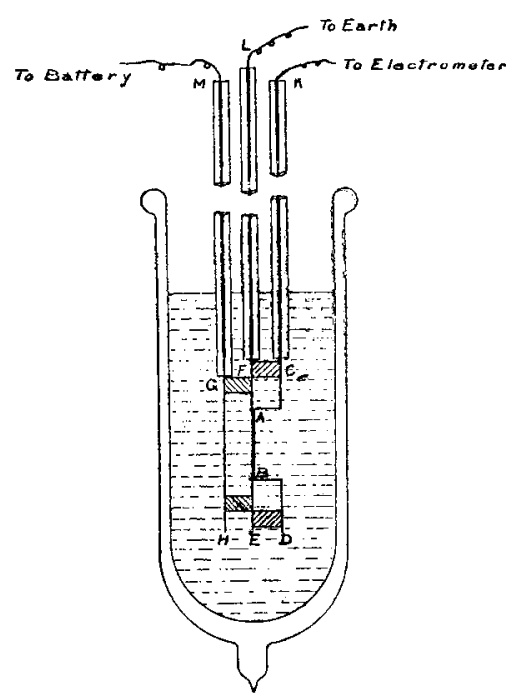

With this arrangement $\mathrm{CABD}$ aeted as an electrode and $\mathrm{EF}$ as a guard-plate for it. The supports to these plates were heavy copper wires about $60 \mathrm{~cm}$. in length. One of them, $\mathrm{KC}$, was surrounded with a tube of clear fased quartz, and the others, LF and MG, with tubes of glass. In making the measurements the wire $I$ was kept connected to earth, the wire $\mathrm{M}$ joined to a battery of storage-cells, and the terminal $\mathrm{K}$ to the free quadrants of the electrometer. The distance between $A B$ and $G H$ was about $5 \mathrm{~mm}$. The capacity of the system, including the electrode $A B$, the free quadrants, and tue leading wires, was in this case about 200 e.s.u.

A number of sets of readings was taken with this apparatus of the conductivity impressed on the liquid air by the rays from polonium, and these readings all gave curves similar to those shown in tig. 2. One set of readings taken in this way is given in Table III. and a curve representing it is shown in fig. 4 (Pl. XVIII.). The shape of this curve, it will be seen, is practically the same as that shown in fig. 2 . 
Table III.

Conductivity imjarted to Liquid Air by Alpha Rays.

\begin{tabular}{|c|c|c|}
\hline $\begin{array}{l}\text { Potential difference } \\
\text { applied to electrodes. }\end{array}$ & $\begin{array}{l}\text { Current (rise in volt- } \\
\text { age) with positive po- } \\
\text { tential applied to GIC. }\end{array}$ & $\begin{array}{l}\text { Current (rise in volt- } \\
\text { age) with neg. pot. } \\
\text { applied to GंH. }\end{array}$ \\
\hline Volts. & Rise in volts per min. & Rise in volts per min. \\
\hline $\begin{array}{c}1367 \\
1069 \\
765 \\
682 \\
645 \\
481 \\
323 \\
251 \\
162 \\
79 \cdot 2 \\
40 \\
20 \cdot 5 \\
16 \cdot 1 \\
10 \cdot 0 \\
8 \cdot 0\end{array}$ & $\begin{array}{l}30 \cdot 35 \times 10^{-2} \\
21.8 \\
16 \cdot 6 \\
16 \cdot 6 \\
15 \cdot 2 \\
14.5 \\
11 \cdot 2 \\
9 \cdot 67 \\
8 \cdot 95 \\
7 \cdot 68 \\
5.38 \\
3 \cdot 91 \\
3 \cdot 91 \\
2 \cdot 88 \\
1.64\end{array}$ & $\begin{array}{l}32 \cdot 7 \times 10^{-2} \\
29 \cdot 24 \\
20 \cdot 76 \\
\ldots \ldots \\
19 \cdot 33 \\
15 \cdot 27 \\
9 \cdot 19 \\
\ldots \ldots \\
8 \cdot 35 \\
6 \cdot 80 \\
5 \cdot 31 \\
4.03 \\
\ldots \ldots \\
3 \cdot 21 \\
\ldots \ldots\end{array}$ \\
\hline
\end{tabular}

It is of interest in connexion with these readings to note that the conductivity obtained with the negative fields was practically the same as that with the positive. This agrees with the results obtained by Greinacher in the ionization of petrol ether by alpha rays. As pointed out before, Greinacher, in the case of his experiments, has drawn the conclusion from his results that the positive and negative ions taking part in the conductivity impressed upon petrol ether by alpha rays have to a very close degree the same mobility. But from some experiments to be described later, it will appear that this conclusion can scarcely be drawn from the results obtained in the liquid air experiments just described.

IV. Ionization in Air at High Pressures by Alpha Rays.

In another set of measurements the system MH, LE, and $\mathrm{KD}$ with the polonium-coated plate $\mathrm{AB}$ in position, fig. 3 , was placed in a receiver with thick steel walls, and air was pumped into it until a pressure of 101 atmospheres was reached. A set of readings similar to those obtained wben the above system was immersed in liquid air was then taken, but in this case, owing to the much greater conductivity which was obtained, a set of sulphur condensers was connected 
in series with the free quadrants. The whole capacity in this case, including quadrants, electrode, condensers, and leading wires, was about 3635 e.s.u. The readings taken with both positive and negative fields are given in Table IV., and the curve corresponding to them is shown in fig. 5 (Pl. XVIII.).

\section{TABLE IV.}

Conductivity impressed upon Air at 101 atmospheres by the Alpha Rays from Polonium.

\begin{tabular}{|c|c|c|}
\hline $\begin{array}{c}\text { Potential difference } \\
\text { applied to measuring } \\
\text { system. }\end{array}$ & $\begin{array}{c}\text { Current (rise in volts) } \\
\text { with positive field. }\end{array}$ & $\begin{array}{c}\text { Current (rise in volts) } \\
\text { with negative field. }\end{array}$ \\
\hline Volts. & Rise in volts per min. & Rise in volts per win. \\
\hline & $62 \cdot 2 \times 10^{-2}$ & \\
\hline 1367 & $51 \cdot 3$ & $58 \cdot 25 \times 10^{-2}$ \\
1069 & $44 \cdot 3$ & $50 \cdot 08$ \\
839 & $38 \cdot 5$ & $42 \cdot 84$ \\
688 & $33 \cdot 6$ & $38 \cdot 24$ \\
562 & $28 \cdot 4$ & 33.46 \\
403 & $22 \cdot 73$ & 28.64 \\
242 & $15 \cdot 23$ & 20.5 \\
79 & $11 \cdot 73$ & $15 \cdot 31$ \\
38 & $9 \cdot 15$ & $12 \cdot 34$ \\
20.5 & $4 \cdot 94$ & $9 \cdot 75$ \\
$10 \cdot 0$ & & $5 \cdot 06$ \\
& & \\
\hline
\end{tabular}

The curve, it will be seen, is in this case practically of the same form as that obtained with the ionization impressed by the rays upon liquid air, and it would appear that here, too, the form of the curve has its explanation : (1) in the formation of ions in the body of the air by some unknown radiation of a more penetrating nature than alpha rays from the poloniumcoated plate, or by the diffusion of ions from the thin ionized layer close to the one electrode into the space between the two electrodes ; and (2) in the gradual lessening of recombination by the applied fields. As the numbers show, the currents with positive and negative fields, just as in the liquid air experiments, were practically the same. In seeking for an explanation of this result, one must bear in mind the work of Kovarik* and of Dempster $\dagger$ on the mobilities of ions produced by alpha rays in gases at high pressures.

In his paper Kovarik has shown that with the air used in his experiments the mobilities of both kinds of ions varied

* Kovarik, Proc. Roy. Soc. A. vol. 1xxxvi. p. 154.

$\dagger$ Dempster, Phys. Rev. vol. xxir. No. 1, p. 53 (1912). 
inversely as the pressure from one to seventy-five atirospheres, and that for the same range of pressures the mobility of the negative ion was about 1.4 times greater than that of the positive. Dempster's results, too, show that at 100 atmospheres the mobility of the negative ion in air was about twice that of the positive ion, but his results indicate that while the mobility of the positive ion varied inversely with the pressure up to 100 atmospheres, the mobility of the negative ion decreased less rapidly as the pressure was increased than it should if it followed the inverse pressure law.

With moist carbon dioxide on the other hand, Kovarik found that the mobilities of positive and negative ions were approximately equal to each other for pressures up to 57 atmospheres, and that the mobilities of both ions decreased with increase of pressure much more rapidly than would be warranted by supposing the inverse pressure law to hold. As the air in the present experiments was obtained from a liquid air compressor and no special pains were taken to dry it, other than passing it through a chamber filled with potassium hydrate, it is possible that the equality in conductivity indicated by the results in Table IV. might, in small part at least, be traceable to the presence of moisture in the air.

It would appear, however, from some work which was dune later, and which is described in section VI., that the equality in the conductivity obtained with positive and negative fields in the experiments just described was due in great measure to the particular form given to the apparatus used in making the measurements. For it was found when the apparatus was considerably modified, that results were obtained which clearly pointed to the mobility of the negative ion produced in air at high pressures by alpha rays being considerably greater than that of the positive. In taking the readings given in Table IV. the capacity of the system was 3635 e. s. units, and as the capacity of the system in the liquid air measurements was only 200 it wunld follow that the conductivity obtained in the air at 101 atmospheres with the highest fields used was about 36 times that obtained with the same field when the ionization was produced in liquid air. This difference was no doubt due to the rapid recombination of the ions which must have taken place in the liquid air. The layer of ionization in the liquid air wonld be considerably narrower than that in the air at the high pressure, and consequently the tendency to recombination would be very much greater in the case of the former than in that of the latter. 


\section{Ionization in Air at Atmospheric Pressure by Alpha Rays.}

In another set of measurements the polonium-coated plate used in the experiments with the liquid air and with the air at the high pressure described in sections III. and IV., was attached to the end of an electrode provided with a guardtube and inserted at the centre of a cylindrical copper ionization-chamber about $10 \mathrm{~cm}$. in diameter and about $12 \mathrm{~cm}$. in length. The air in this cylinder was kept at atmospheric pressure, and as the range of the alpha rays from polonium is about $3.8 \mathrm{~cm}$. in air at this pressure it is clear that the dimensions of the receiver were such as to insure the complete absorption of all the alpha radiation emitted by the plate. The electrode was connected as before to the quadrants of the electrometer, and the currents were measured with different fields applied to the region traversed by the rays. Here again it was found necessary to attach a sulphur condenser of high capacity to the quadrant system in order to take the readings conveniently. The total capacity of the measuring system used in this case was 8142 e.s.u.

A set of readings taken with this arrangement both with positive and negative potentials applied to the cylindrical receiver is given in Table V., and the curves corresponding to these are shown in fig. 6 (Pl. XVIII.).

\section{Table V.}

Ionization produced in air at Atmospheric Pressure by the Alpha Rays from the Polonium.

\begin{tabular}{|c|c|c|}
\hline $\begin{array}{c}\text { Potential applied } \\
\text { to receiver. }\end{array}$ & $\begin{array}{c}\text { Current (rise in volts) } \\
\text { with positive field. }\end{array}$ & $\begin{array}{c}\text { Current (rise in volts) } \\
\text { with negative field. }\end{array}$ \\
\hline Volts. & Volts per min. & Volts per min. \\
\hline & $3 \cdot 71$ & \\
730 & $3 \cdot 71$ & $4 \cdot 23$ \\
538 & 3.66 & $4 \cdot 18$ \\
445 & 376 & $4 \cdot 23$ \\
382 & 3.32 & $4 \cdot 18$ \\
213 & $3 \cdot 06$ & $3 \cdot 98$ \\
130 & 271 & 355 \\
79 & 1.96 & $3 \cdot 00$ \\
385 & -96 & $1 \cdot 85$ \\
$20 \cdot 5$ & -35 & 93 \\
10 & & -34 \\
\hline
\end{tabular}


Here it will be seen the readings obtained with negative fields were considerably higher than those obtained under corresponding voltages with positive fields. 'This no doubt arose from the mobility of the positive ion being less than that of the negative. With both fields it will be seen saturation-currents were obtained with potentials of approximately 400 volts applied to the cylinder.

As the capacity of the measuring system was 8142 e.s.u., it will be seen from the readings given in the table that the maximum conductivity in this case was about 16 times greater than the maximum obtained with the complete absorption of the same radiation by air at 101 atmospheres, and consequently about 576 times greater than the greatest conductivity measured when the same radiation was absorbed by liquid air. The general results of these measurements therefore agree with those obtained by Greinacher with the liquids which be used, inasmuch as they show (i.) that it is very much more difficult to obtain saturation-currents with ionization in liquid air by alpha rays than when the jonization was produced by the same radiation in air at ordinary pressure, and (ii.) that the currents obtainable with a given field under ionization by alpha rays are very much less with liquid air than with air at ordinary pressures.

\section{Mobilities of Ions produced by Alpha Rays in Air at High Pressures.}

In order to clear up if possible the question of the relative mobilities of ions produced by alpha rays in air at high pressures, the apparatus shown in fig. 7 was used.

Fig. 7.
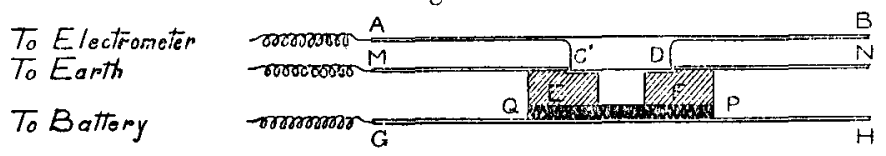

$A B$ was a brass plate about $8 \mathrm{~cm}$. long carrying a boss of the same metal, $\mathrm{CD}$, about $2 \mathrm{~cm}$. in diameter. $\mathrm{M} N$ was a second brass plate attached to $\mathrm{AB}$ by insulating supports. This plate was provided with a circular opening as shown in the diagram and acterl as a guard-plate to the boss CI). A third brass plate GH carried a polonium-coated plate $P Q$ with the coated surface facing the boss CD. EF was a plate of ebonite provided with a circular opening and inserted between the polonium-coated plate $\mathrm{PQ}$ and the guard-plate MN and the boss CD. (Gare was taken in 
putting this apparatus together to see that the boss CD did not touch either the plate $\mathrm{MN}$ or the ebonite plate $\mathrm{EF}$. The diameter of the opening in EF was $1.06 \mathrm{~cm}$., and the distance between the boss CD and the face of the plate $P Q$ towards it was $1 \mathrm{~cm}$. This apparatus was placed in a strong steel cylinder and air was pumped into the latter until the pressure stood at 120 kilograms per $s q . \mathrm{cm}$. The plate $A B$ was attached to an insulated wire leading through the cylinder and passing on to the quadrants of a Dolezalek electrometer. The plate M was connected directly to the steel cylinder, which was kept joined to earth, and the plate GH was connected by an insulated wire passing through the cylinder to a battery of storage-cells. It should be added that the apparatus was put together initially without the polonium-coated plate $P Q$ in position and was found to insulate perfectly when surrounded with air in the steel cylinder at 120 kilograms per sq. cm. pressure.

With the polonium-coated plate in position one had with this arrangement a layer of highly ionized air close to the plate $\mathrm{PQ}$. Moreover, the field between the plate $\mathrm{PQ}$ and the boss CD was a uniform one, and the dimensions of the field through which conduction could take place to the electrode CD were perfectly defined.

When this apparatus was put together and air pumped into the cylinder it was left intact for a period of over five months, and at intervals during this time sets of readings on the current between $\mathrm{CD}$ and $\mathrm{PQ}$ were taken with series of gradually increasing potentials both positive and negative applied to GH. Throughout the whole of this period the currents for selected fields up to about 750 volts remained practically the same, which showed, since the intensity of the radiation from the polonium must bave diminished by over one half in this time, that the current was independent of any variations which took place in the ionization layer.

For such a case as this Rutherford ${ }^{*}$ and Child $\dagger$ have shown that the mobilities of the ions (expressed in electrostatic units) taking part in the conduction may be deduced from the relation

$$
k=\frac{32 \cdot \pi \cdot d^{3} \cdot i}{9 \mathrm{~V}^{2}} \cdot . \cdot \cdot . \cdot
$$

where $i$ is the current per sq. cm. cross-section, $d$ the distance and $V$ the potential difference between the electrodes.

If practical electromagnetic units be used the mobility is

* Rutherford, Phys. Rev. vol. xiii. (6) p. 321 (1901).

t Child, Phys. Rev. vol, xii. (3) p. 137 (1901). 
890 Prof. McLennan and Mr. Keys on the Electrical

given by

$$
k=32 \cdot \pi \cdot \frac{d^{3} \cdot i \cdot 10^{11}}{V^{2}} \mathrm{~cm} . \text { a sec. per volt a cm., . . }
$$

where $i$ is expressed in amperes, $\mathrm{V}$ is in volts, and $d$ in $\mathrm{cm}$.

If $c$ be the capacity in e.s.u. of the electrode $A B$ to grether with the leading wires, quadrants, and attached condensers to which it is connected; $r$ the radius of the opening in the ebonite plate EF, $x$ the number of scale-divisions which correspond to a potential of 1 volt applied to the quadrants, and $y$ the number of scale-divisions per min. corresponding to the current between the two electrodes for a given applied ficld, then $i$ in equation (1) is given by

and therefore

$$
i=\frac{c}{9 \cdot 10^{11}} \cdot \frac{y}{b 0} \cdot \frac{i}{\pi r^{2}} \text { amperes, }
$$

$$
\begin{aligned}
k & =\frac{32 \cdot \pi \cdot d^{3}}{\mathrm{~V}^{2}} \cdot 10^{11} \cdot \frac{y c}{x \cdot 60 \cdot 9 \cdot 10^{11} \cdot \pi \cdot r^{2}} \\
& =\frac{8 d^{3} \cdot y \cdot c}{135 \mathrm{~V}^{2} \cdot r^{2} \cdot x} .
\end{aligned}
$$

Since with the apparatus used $d=1 \mathrm{~cm}$. and $r=53 \mathrm{~cm}$. it follows that $k$ is given by

$$
k=21 \frac{c}{x} \cdot \frac{y}{V^{2}} .
$$

For a selected pressure this relation shows that $y$ should

\begin{tabular}{|c|c|c|c|c|c|}
\hline \multicolumn{6}{|c|}{ No. of Scale-rlivisions per volt $=x=400$. } \\
\hline \multicolumn{3}{|c|}{ Yositive field. } & \multicolumn{3}{|c|}{ Negative field. } \\
\hline Values of $y$. & $\underset{\text { (in volts). }}{\mathbf{V}}$ & $\begin{array}{c}\nabla^{2} \\
\text { (in rolts). }\end{array}$ & Values of $y$. & $\underset{\text { (in rolts). }}{\mathrm{V}}$ & $\begin{array}{c}\mathrm{V}^{2} \\
\text { (in volts) }\end{array}$ \\
\hline $2 \cdot 3$ & 83.1 & 63056 & 39 & $80 \cdot 0$ & $\overrightarrow{6400} \cdot 0$ \\
\hline $10 \cdot 7$ & 1620 & $26,24+0$ & 11.3 & $160 \%$ & $25,600-0$ \\
\hline $25 \cdot 5$ & 2420 & $58,50 \pm 0$ & $35 \cdot 2$ & 243.0 & 59,0490 \\
\hline $51 \cdot 6$ & 3220 & $107,584: 0$ & $71 \cdot 4$ & 328.0 & $107,584 \cdot 0$ \\
\hline $7+5$ & 4100 & $168,100 \cdot 0$ & 104.7 & $410 \cdot 0$ & $168.100 \cdot 0$ \\
\hline 101.6 & 4900 & 240,1000 & $130 \cdot 0$ & 490.0 & $240,100^{\circ}$ \\
\hline $147 \cdot 3$ & $564 \cdot 0$ & 318,0960 & $164: 3$ & 56500 & 310,2250 \\
\hline 2028 & 6300 & 396,9000 & $220 \cdot i$ & $631 \% 0$ & $396,900 \cdot 0$ \\
\hline $2 \pm 7 \cdot 8$ & $732 \cdot 0$ & $535,8 \div 40$ & 2758 & $730 \cdot 0$ & 532,9000 \\
\hline 2928 & $832 \cdot 0$ & $777,92 \pm 0$ & & & \\
\hline
\end{tabular}
be proportional to $V^{2}$.

One set of readings from a number taken with this apparatus is given in Table VI., and curves drawn from

$$
\text { TABLe VI. }
$$



them are shown in figs. 8 and 9 (Pl. XVIII.). In both diagrams the values of " $y$ " are taken as ordinates, but the values of " $V$ " are taken as abscissæ in fig. 8 and the values of $\mathrm{V}^{2}$ in fig. 9.

TABle VII.

\begin{tabular}{|c|c|c|c|}
\hline \multicolumn{4}{|c|}{$\begin{array}{c}\text { Mobility of positive ion }=k_{1 *} \text { Mobility of negative ion }=k_{2} \\
\text { Pressure }=116.1 \text { atmospheres. }\end{array}$} \\
\hline \multicolumn{2}{|c|}{ Positive ion. } & \multicolumn{2}{|c|}{ Negative ion. } \\
\hline $\begin{array}{l}k_{1}= \\
0.0005294\end{array}$ & $\begin{array}{l}\text { P. } k_{1}= \\
0.06152 .\end{array}$ & $\begin{array}{l}k_{2}= \\
0.0006217\end{array}$ & $\begin{array}{l}\text { P. } k_{2}= \\
0.072 * 24 .\end{array}$ \\
\hline \multicolumn{4}{|c|}{ Ratio $k_{2} / k_{1} \equiv 1 \cdot 18$} \\
\hline \multicolumn{4}{|c|}{$\begin{array}{c}\text { Kovarik's Results for pressures up to } 7 \bar{o} \text { atmospheres. } \\
\text { P. } k_{1}=1.346 . \quad \text { P. } k_{2}=189 .\end{array}$} \\
\hline
\end{tabular}

From the numbers given in Table VII. and from the curves in figs. 8 and 9 , it will be seen that for potentials up to about 800 volts, the relation between $y$ and $\mathrm{V}^{2}$ is practically a linear one, and that the mobility of the negative ion is about 18 per cent. greater than that of the positive. This would go to show that one is warranted in applying the Rutherford-Child relation to the present experiments. But the absolute values of the mobilities which have been deducod from the numbers given in Table VII. are much smaller than one should expect them to be if the inverse pressure law applied up to 116 atmospheres.

Kovarik has shown that this law applies in the case of air up to 75 atmospheres, and for positive ions up to this limit he finds $p k_{1}=1 \cdot 346$ and for the negative $p k_{2}=1 \cdot 89$. The mobility for the positive ion deduced from these experiments is there only about $1 / 22$ and that of the negative ion $1 / 26$ of what one should expect to get if the inverse pressure law held between 75 and 116 atmospheres. If the results obtained be correct it would follow that the inverse pressure law does not apply in this region.

On the other hand, it is just possible that one is not justified in assuming the effective cross-section of the flow of current between the electrodes to be the area of the opening in the ebonite plate EF. There would be a tendency for the ions in passing across the field to diffuse to the walls of this opening, and if such diffusion did occur 


\section{Prof. McLennan and Mr. Keys on the Electrical}

the effect would be to reduce the effective area of the opening. This would result in the values of the mobilities deduced as above being smaller than they really should be. However, one would scarcely expect the reduction from values calculated on the basis of the inverse pressure law to be so great as that indicated by the numbers given in Table VII.

A circumstance which seemed to point to diffusion exerting an influence on the readings was a time effect which was observed especially when low fields were used. With fields below 60 volts a centimetre this was particularly marked, and it occurred with both positive and negative fields. Where such fields were applied after the various parts of the apparatus had remained uncharged for some time, a gradual diminution in the intensity of the current was always observed in taking a series of successive readings.

It required about half an hour to elarse after the field was applied before the current reached a limiting value, and the diminution in current amounted to from 12 to 20 per cent. With fields above 60 volts a centimetre the effect gradually disappeared, and when fields of 250 volts a centimetre and higher were applied no diminution in the current was observed. This effect would seem to indicate that the walls of the opening in the ebonite plate gradually became charged by ions diffusing to them. One effect of this action would be to produce a partial neutralization of the field, and this in turn would account for the falling off in the current.

As this effect was absent when the higher fields were applied it is not clear why such small values were obtained for the mobilities. It may be added that the readings given in Table VII. were all taken immediately after the application of the field.

It was the intention of the writers to use the apparatus to determine the mobilities of the ions produced in liquid air by alpha rays, but in view of the small values obtained with it for $k_{1}$ and $k_{2}$ in air at the particular pressure of 116 atmospheres it seemed advisable to defer these measurements until more extended observations were made on the mobilities of the ions in air at a series of bigh pressures. The poloniumcoated plate used above was of rather small dimensions, but it was all that was available at the time the experiments were made. With a larger plate the effects of diffusion should be lessened.

The experiments made so far show that there should be no great difficulty in finding the mobilities of ions produced in air up to and even beyond 150 atmospheres. 'The difficulty in determining the mobilities in liquid air will be largely one of getting rid of the formation of air-bubbles in the tield 
and of preventing the liquid air from becoming contaminated with ice-crystals.

In order to ascertain the mobilities of the ions in liquid air and over as large a range of pressure as possible, and especially to clear up any doubt regarding the results oltained in the present experiments on the mobilities at 116 atmospheres, the investigation is being continued with a polonium-coated plate of larger area.

\section{On the Existence of a Penetrating Radiation emitted by Polonium.}

In the earlier portion of the paper when dealing with the conductivities represented by the curves shown in figs. 2,4 , and 5, it was suggested in explanation of the bend in the curves that possibly this effect might be due to a small volume ionization in the field due to a penetrating radiation from the polonium. That such a volume ionization did really exist was shown by means of the apparatus given in fig. 7 before it was put together for the experiments described in section VI.

In place of its being constructed as shown in the diagram the ebonite plate was not inserted, but in its place a sheet of finely meshed gauze was fixed parallel to the two plates $\mathrm{GH}$ and $\mathrm{MN}$, and about half-way between them. The edges of this gauze sheet were turned down and soldered to the plate GH. The polonium-coated plate was close to the plate $\mathrm{GH}$, and so within the space between it and the gauze.

The apparatus as constructed in this way was placed in the steel receiver, which was then filled up with air to over 100 atmospheres. The distance between the gauze and the plate $P Q$ was about 3.5 millimetres, and as the alpha rays emitted by the polonium could not have a greater range at this high pressure than a fraction of a millimetre, it is clear that these rays could not produce any ionization in the space between the gauze and the plate $M N$. On applying a potential difference, however, between the gauze and the plate MN a well-marked though small current was obtained which reached saturation with a field of about 20 volts; this current was obtained with positive as well as with negative fields, and with both fields its maximum intensity was the same. This result, combined with the fact that the mobilities of the ions are exceedingly small at the high pressure used, would seem to show that the current had its origin in ionization produced in the space between the gauze and the plate MN by a penetrating radiation from the polonium rather than in ions diffusing through the gauze into this space from the ionized layer close to $P Q$. The apparatus 


\section{4}

Conductivity imparted to Liquid Air by Alpha Rays.

was not suitable for testing whether this radiation was magnetically deflectable or not, but in view of the experiments of Chadwick*, which show that gamma rays are produced by alpha rays in certain eircumstances, the results would seem to point to the existence of gamma rays accompanying the alpha ravs from polonium. The probability of this conclusion being correct is increased when it is remembered that the experiments were made with a layer of polonium which had been deposited on the copper plate $P Q$ about nine months previously. This interval should have been sufficient for any beta-ray product to have died ont which with any likelibood might lave originally contaminated the polonium deposit.

\section{Summary of Results.}

(1) In a number of experiments it has been shown, in agreement with a number of other experimenters, that liquid air when freshly filtered is an extremely good insulator, and that its conductivity in the absence of any ionizing radiation other than that from the earth is much the sume as that of ordinary clean air at atmospheric pressure.

(2) 'The dielectric constant of liquid air was found to be 1.43 .

(3) The saturation-current obtained in air at ordinary pressure by the complete absorption of the alpha radiation emitted by a plate coated with polonium, was found to be about 16 times the maximum current obtained with the highest fields used when the radiation was absorbed in air at 101 atmospheres, and about 576 times the maximum current obtained in liquid air when the ionization was produced by the same radiation.

(4) The mobility of the positive ion produced in air at 116 atmospheres by alpha rays was found to be 0.0005294 cm. sec. per vclt cm. and that of the negative $0.0006217 \mathrm{~cm}$. sec. per volt $\mathrm{cm}$, the latter being about $1 \cdot 18$ times the former.

(5) Evidence has been found in the course of the investigation of the existence of a penetrating radiation emitted by the layer of polonium which furnished the alpha rays.

In conclusion the authors wish to acknowledge the kindness of Prof. H. A. Dawes and Mr. P. Blackman who assisted in taking readings during the course of the investigation.

The Physical Laboratory,

University of Tornnto,

June Ist, 1913. (1913).

* Chad wick, Phil. Mag. vol. xxiv. p. 494 (1912) ; vol. xxv. p. 193 
McLennan \& Keys.

FIG. 2.
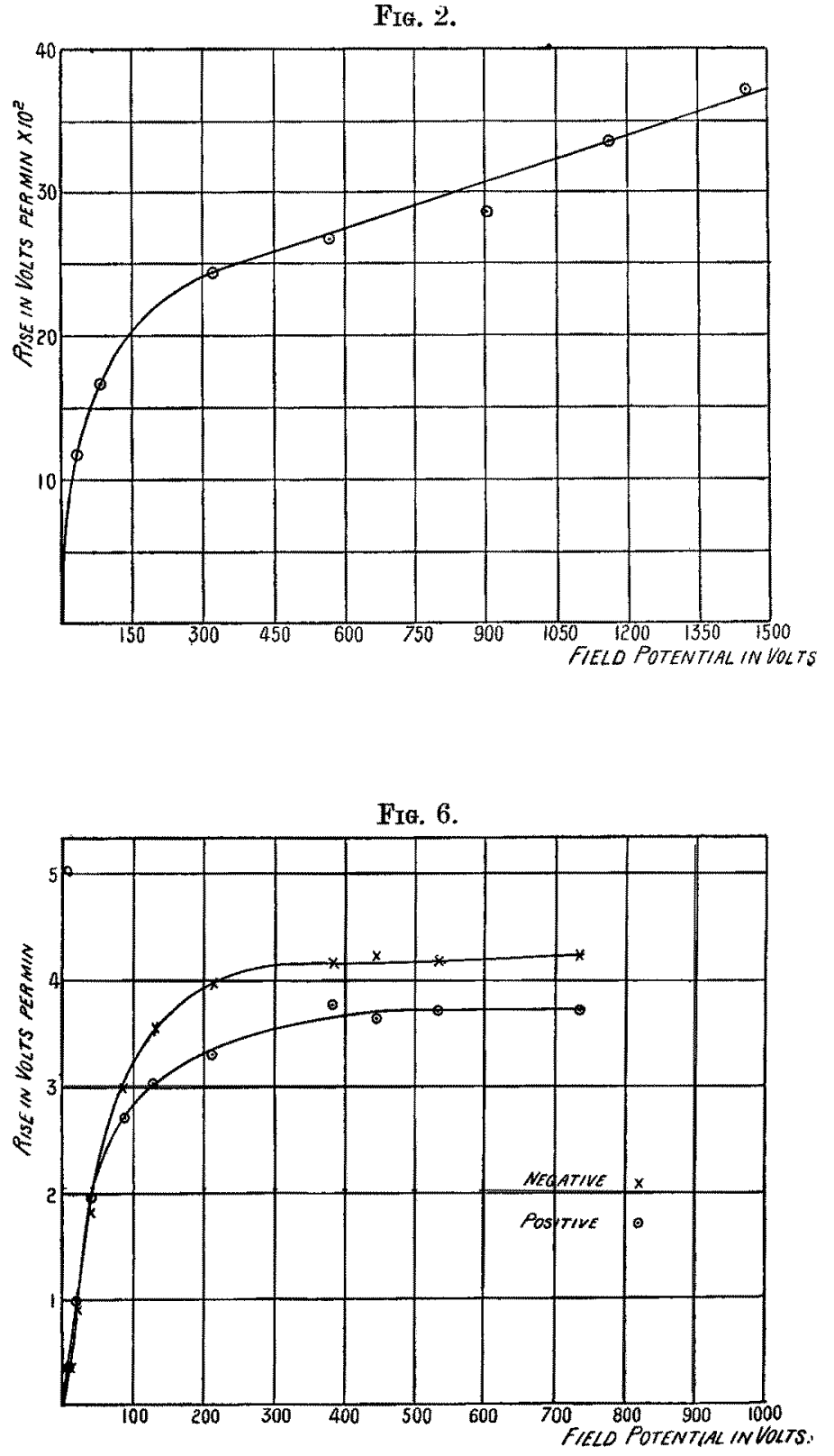

Fig. 4.

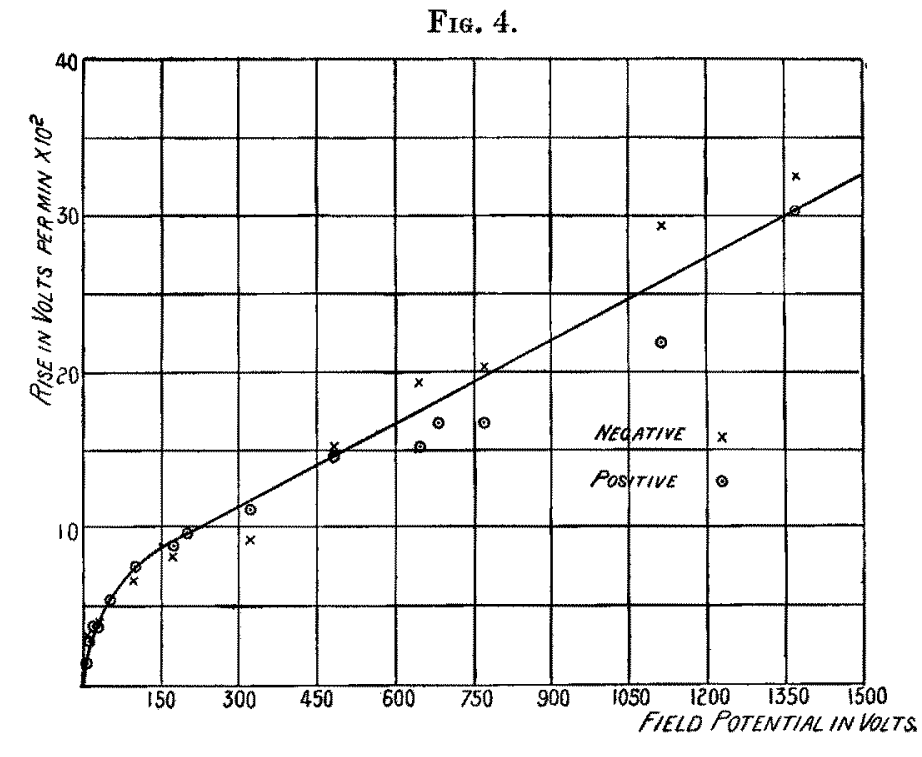

Fit. 8.

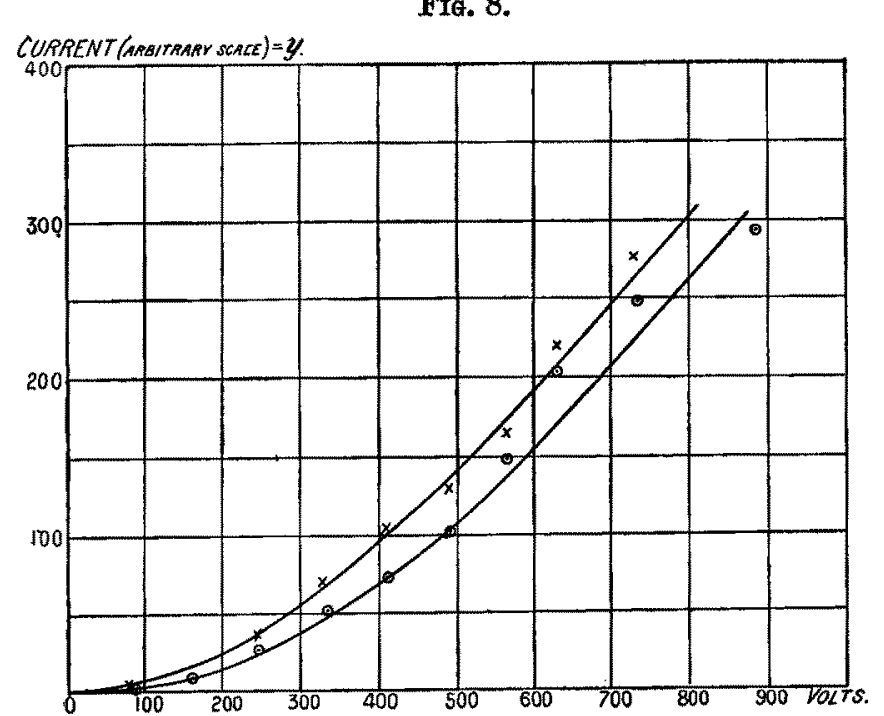

Phil. Mag, Ser. 6. Vol. 26, P1. XVIII. Fra. 5.

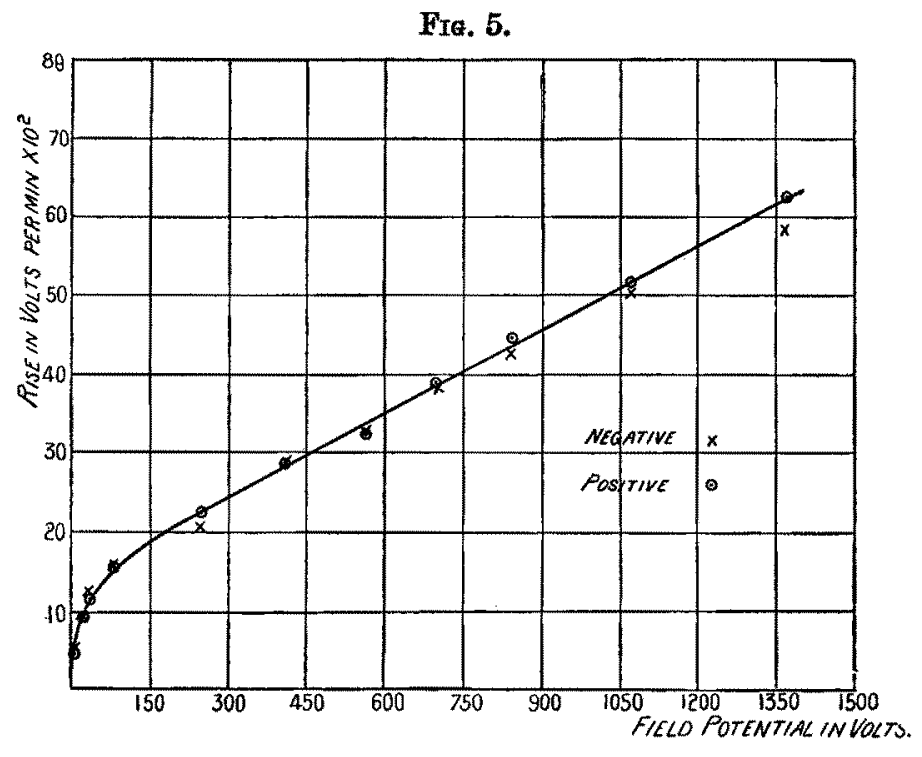

Fra. 9.

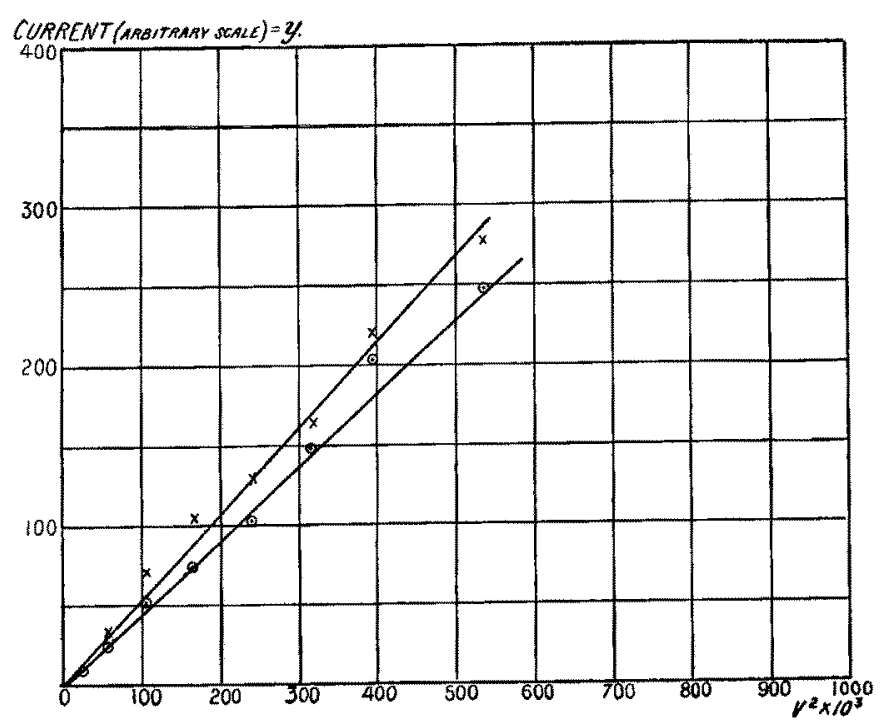

